\title{
Internet Gaming Addiction Presenting as Withdrawal Psychosis: An Unusual Case Report
}

\author{
${ }^{1}$ Prosenjit Ghosh, ${ }^{2}$ Sujit Sarkhel
}

\begin{abstract}
Introduction: In the new generation, the Internet has become an important tool for education, entertainment, communication, and information-sharing. Easy access and anonymity are two of the several aspects of the Internet fostering addictive behavior.

Case History: We report a case of young adult addicted to online mobile gaming (IAD/IUD) for 2 years and presenting with features of withdrawal psychosis following two weeks of cutting down gaming behavior.
\end{abstract}

Discussion: There are basically five types of internet addictionOnline gaming, online gambling, online auction, online chatting and cybersex. Gaming addiction is probably the most talked about internet addiction. Probably because we are seeing so many children and adolescence losing control on this type of internet addiction.

Conclusion: Further studies are necessary to investigate the nature and course of withdrawal symptoms associated with IAD/ IUD and to compare with those of substance use disorders and other forms of behavior addiction.

Keywords: Behavioral addiction, Internet use disorder, Multiplayer online battle arena, Online gaming.

How to cite this article: Ghosh P, Sarkhel S. Internet Gaming Addiction Presenting as Withdrawal Psychosis: An Unusual Case Report. Ind J Priv Psychiatry 2018;12(1):34-37.

\section{Source of support: Nil}

Conflict of interest: None

\section{INTRODUCTION}

The internet has become an important tool for education, entertainment, and information-sharing. The main reasons for developing internet addiction are easy to access and anonymity. ${ }^{1}$ Massive rise in access to the internet globally, with the low cost of smartphones/gadgets, the phenomenon of "internet addiction" is emerging as a significant behavioral addiction problem worldwide. ${ }^{2}$ It is estimated that India which presently has 205 million

\footnotetext{
${ }^{1}$ Assistant Professor, ${ }^{2}$ Associate Professor

${ }^{1}$ Department of Psychiatry, Silchar Medical College, Silchar, Assam, India

${ }^{2}$ Institute of Psychiatry, Kolkata, West Bengal, India

Corresponding Author: Prosenjit Ghosh, Assistant Professor Department of Psychiatry, Silchar Medical College, Silchar, Assam, India, e-mail: P_ghosh72@yahoo.com
}

internet users will soon surpass China which currently has the highest Internet user base of 300 million. $^{3}$

Internet addiction in young adults can have a deleterious effect on identity formation and may adversely affect cognitive functioning, hamper academic performance and promote impulsive activities, and lead to poor dietary habits. ${ }^{4}$

College students are vulnerable to developing Internet addiction due to the following factors: ease of use; limited or no parental supervision; it is cheap; the internet offering a route of escape from exam stress. ${ }^{5}$

After more than 20 years of coining the term IAD, there still remains nosological confusion regarding the exact place of this disorder in the diagnostic system. In diagnostic and statistical manual of mental disorders $(\mathrm{DSM}-\mathrm{V})$, Internet addiction is mentioned as an area in need of further research. ${ }^{6}$

American Society of Addiction Medicine ${ }^{7}$ in 2011 defined addiction as "a primary, chronic disease of brain reward, motivation, memory, and related circuitry. Dysfunction in these circuits leads to characteristic biological, psychological, social and spiritual manifestations. This is reflected in an individual pathologically pursuing reward and/or relief by substance use and other behaviors".

Goel et al. ${ }^{8}$ in 2013, evaluated 987 students of various institutes in Mumbai with young internet addiction scale and reported a prevalence of Internet Addiction to be $7 \%$.

Krishnamurthy et al. ${ }^{9}$ in 2015 studied 545 college students in Bangalore and reported lifetime estimate of comorbid substance abuse as high as $38 \%$ among the students diagnosed as having internet addiction.

Here, we report a case of an adult patient with IAD who developed a psychotic episode along with withdrawal features after sudden discontinuation of long-term excessive Internet use.

\section{CASE HISTORY}

A26-year old young man $\mathrm{Mr} B \mathrm{BD}$ presented in the chamber on 22nd May 2018 with the chief complains of decreased sleep, fearfulness, irrelevant talk, hearing voices, always clinging to his mother, reduced oral intake and talking about internet game mobile legends for about four days. On detail history taking it was known that Mr BD suddenly started to behave abnormally and started to feel 
fearful that some of his friends are trying to harm him and his parents and he never used to let his parents leave him alone. He used to hear the voices of both men and women at odd hours just outside his house. He cautioned his parents not to open the door to anyone. His sleep was very much disturbed, and he could hardly sleep for a couple of hours at night. At daytime, he always used to stay close to his mother and at times was very restless.

He had no history of any psychiatric or neurological illness. His father was suffering from the depressive disorder and was on antidepressants, and for the time being was asymptomatic. His birth and early childhood history revealed no significant events. He was an average student, but for last couple of years his academic performance deteriorated, and at the age of 26 years he was still in the second year of a degree course.

He was regularly consuming Indian made foreign liquor 5 to 6 drinks $(60 \mathrm{~mL})$ per month for last one year; there was no history of day drinking, solitary drinking, withdrawal fits or blackout. He also has been consuming cannabis for last two years with an average consumption 6 to 7 cones in shorter (some sort of device to take cannabis) in a week. He used to take cannabis with his friends.

He also disclosed that for last two years he has been playing online video game known as mobile legends with gradually increasing time spent on playing the game. He always used to carry two smartphones and used to become furious if his parents asked to see his mobile or enquired about his whereabouts. Most of the time of the day he used to stay outside the home and used to bunk his classes. Gradually he used to spend less and less time with his parents and returned home late at night. His food intake and self-care was also neglected for the last 7 to 8 months because of his gaming behavior. He told that the game was played from smartphone after creating an account and he used to play with nine of his friends. It was an online game, and an internet connection was required. Each team consists of five players, and each player has to choose a hero/character. The game has to be purchased from the play store. After starting the game, there are three lanes-top lane, bottom lane, and middle lane. The aim of each team is to destroy the base of the opponent team by killing the Heroes of the enemy team. There are usually three big towers which has to be destroyed to earn gold and other incentives. He also revealed that for last two weeks he was trying to cut down his gaming behavior and avoiding his online friends.

He had no history of any homo/heterosexual relationships. Premorbidly he was social, religious, cooperative and a charming boy.

His physical or neurological examination did not reveal any significant abnormality. His laboratory examinations including-liver function test, kidney function test, serum electrolytes, complete blood count, virology tests and computed tomography (CT) scan brain did not reveal any abnormalities.

\section{Mental Status Examination}

Mr BD was a young man of average built, increased psychomotor activity, disheveled appearance, poor hygiene, partially cooperative, looking perplexed with scanning look and hallucinatory behavior. Rapport was not well established. He was seen muttering at times.

The speech was spontaneous, increased volume, normal reaction time, most of the times relevant but occasionally irrelevant. His mood was unpleasant; affect was anxious and irritable, appropriate with normal range and intensity.

He was having the delusion of persecution, the delusion of reference. He also had overvalued ideas of the heroes of his opponent team coming to his home. He had auditory hallucination in the third person. The voices were that of the members of his opponent team of the Mobile game.

He was conscious; comprehension was intact, his attention and concentrations were impaired. His judgment and reasoning was impaired. Abstract thinking could not be assessed. Memory and intelligence were intact. His insight was grade II.

He was given Young's internet addiction test, and his score was 81 . Although he was abusing both alcohol and cannabis, he did not fulfill the criteria of Dependence for both the substances according to ICD guidelines.

He was provisionally diagnosed as a case of IAD/ IUD with polysubstance abuse presenting as acute transient psychotic disorder with withdrawal symptoms. He has prescribed risperidone $6 \mathrm{mg}$ in divided doses with lorazepam $2 \mathrm{mg}$ at bedtime. He became highly restless and aggressive and the next day was admitted in hospital and was treated with injectable lorazepam, injectable haloperidol, and supportive medicines and after eight days was discharged from the hospital. Till date, he is doing well and is maintaining abstinence.

\section{DISCUSSION}

Internet addiction disorder (IAD) is highly prevalent in adults, adolescents and even in children and has a serious impact on mental health. Christakis reports that $2-18 \%$ of Asian children are addicted to the Internet ${ }^{10}$ and researchers also attributed internet use with severe psychopathology and impairment in functioning. ${ }^{11,12}$ Prolonged internet use can induce decreased gray matter volume in certain areas of the brain. ${ }^{13}$ 
The concept of behavioral addiction has gained ground after the 2011 definition of addiction proposed by American Society of Addiction Medicine (ASAM). The internet addiction share with substance use disorder-tolerance, craving, withdrawal, and impairments in social/financial/occupational areas and brain damage.

A study on IAD revealed that $95.5 \%$ of the patients experienced withdrawal symptoms, making these as the second commonest symptoms after preoccupation $(96.4 \%) .{ }^{14}$ Withdrawal symptoms are frequent and have diagnostic value in the overall management of IAD. Recently, two case reports have described the emergence of psychotic symptoms during withdrawal from Internet addiction. ${ }^{14,15}$

In 1995, Ms Kimberly Young, conceived of "addictive use of the internet" as a pathological condition. ${ }^{16}$ The term "internet addiction" has many competing contenders; some of the important ones are pathological Internet use, problematic Internet use (PIU), internet use disorder (IUD), and pathological use of electronic media among others.

There are five types of internet addiction-online gaming, online gambling, online auction, online chatting, and cybersex. Gaming addiction is probably the most talked about internet addiction as the huge number of children and adolescents get involved and lose control. The most addictive games are played in real time with real people.

Our patient used to spend 8-10 hours a day in playing mobile legends, an online real-time video game, a type of multiplayer online battle arena, in which each player controls one character in a team and competes with another team. The main aim is to demolish the opposing team's main structure with the help of episodically released units that march forward along set paths.

The two opposing teams will have to destroy their enemy's base to win. Each team most usually consists of five players. Often, there is one major structure which must be destroyed to win; although there are few defensive structures to prevent this. ${ }^{17}$ There are typically three "lanes" that are the major ways of getting from one base to another.

Each player of a team controls a single powerful unit generally called a 'hero'. Whenever a hero kills an enemy unit, it gains points which allow the hero to level up. When a hero dies, it has to wait for a specific time period, before it can revive at the home team's base. ${ }^{18}$

Moderate amounts of gold are rewarded to the Hero for destroying hostile computer-controlled units, and larger amounts are rewarded for killing enemy Heroes. Gold is used by heroes to purchase many items that can improve the combat efficacy of the hero. ${ }^{19}$
Just like substance use disorder, many patients with IAD show withdrawal symptoms; however, most typically report mood or anxiety symptoms such as dysphoria, anxiety, irritability and anger outbursts ${ }^{14}$. Individuals with a chemical addiction often show psychotic symptoms; almost half of those who abuse cocaine $(47.7 \%)$ or cannabis $(44.8 \%)$ report experiencing psychotic symptoms either during the use or withdrawal of those specific substances. ${ }^{20}$ Our case suggests that behavior addiction such as IAD may also cause withdrawal psychosis in some vulnerable individuals. One study found that $22 \%(4 / 18)$ of pathological gamblers without comorbid alcohol dependence reported that they often experience hallucinations as withdrawal symptoms. ${ }^{21}$

The contents of hallucinations and theme of delusion also reflected the contents of the game in our patient. Auditory hallucinations from men and women may reflect actual voices of the game characters. Additionally, attacking his parents with weapons is similar to one of the main themes of the game (i.e., kill the enemy with various weapons).

Differential diagnosis of this case included substanceinduced psychosis and bipolar one disorder, single episode mania with psychotic features. Information from family members and psychological and laboratory tests did not support the possibility of a psychotic disorder associated with substance abuse or a general medical condition. Also, he did not meet criteria for a mood episode, although he demonstrated irritability throughout the illness.

Dalal and $\mathrm{Basu}^{22}$ opined in an editorial in Indian Journal of Psychiatry in 2016 "There are people out there who are suffering because of their dysfunctional use of the Internet. They need help, and at least some of them can be helped. There is enough evidence to suggest that Internet addiction (or what we prefer to call IUD, in line with substance use disorders of DSM-5) can no longer be considered a fad".

Given the emergence of withdrawal psychosis, in this case, IAD/IUD may be better categorized as an addiction rather than impulse control disorder. Internet addiction may lead to abnormal changes in brain structure and function that are similar to those observed in chemical substance dependency. Further studies are necessary to investigate the nature and course of withdrawal symptoms associated with IAD/IUD and to compare with those of substance use disorders and other forms of behavior addiction.

Thus, there is a clinical utility and public health perspective to the whole question of IUD, although some may call this condition a nosological orphan or nosological immigrant. 


\section{REFERENCES}

1. Kuss DJ, Griffiths MD. Online social networking and addiction-A review of the psychological literature. Int J Environ Res Public Health 2011;8:3528-3552.

2. Christakis DA. Internet addiction: A 21st century epidemic? BMC Med 2010;8:61.

3. Internet and Mobile Association of India. Internet Users in India Crosses 200 Million Mark. New Delhi: Internet and Mobile Association of India (IMAI); 2013.

4. Pfaff DW. Neuroscience in the 21st Century: From Basic to Clinical. New York: Springer; 2013.

5. Kandell JJ. Internet addiction on campus: The vulnerability of college student. Cyberpsychol Behav 1998;1:11-17.

6. American Psychiatric Association. Diagnostic and Statistical Manual of Mental Disorders. 5th ed. Arlington, VA: American Psychiatric Publishing; 2013. pp. 796.

7. American Society of Addiction Medicine. Public Policy Statement: Definition of Addiction. https:/ / www.asam.org/ resources/definition-of-addiction.

8. Deepak Goel, Alka Subramanyam, Ravindra Kamath. A study on the prevalence of internet addiction and its association with psychopathology in Indian adolescents. Indian Journal of Psychiatry. 2013;55(2):140-143.

9. Sharmitha Krishnamurthy, Satish Kumar Chetlapalli. Internet addiction: Prevalence and risk factors: A cross-sectional study among college students in Bengaluru, the Silicon Valley of India. Indian Journal of Public Health.2015;59(2):115-121.

10. Christakis DA. Internet addiction: a 21st century epidemic? BMC Med. 2010;8:61.

11. Flisher C. Getting plugged in: an overview of internet addiction. J Paediatr Child Health. 2010;46:557-559.

12. Murali V, George S. Lost online: an overview of Internet addiction. Adv Psychiatr Treat. 2007;13:24-30.
13. Yuan K, Qin W, Wang G, Zeng F, Zhao L, Yang X, et al. Microstructure abnormalities in adolescents with Internet addiction disorder. PLoS One. 2011;6:e20708.

14. Tao R, Huang X, Wang J, Zhang H, Zhang Y, Li M. Proposed diagnostic criteria for Internet addiction. Addiction. 2010;105:556-564.

15. Ahyoung Paik, Daeyoung Oh, ${ }^{*}$ and Daeho Kim. A Case of Withdrawal Psychosis from Internet Addiction Disorder. Psychiatry Investig. 2014 Apr;11(2):207-209.

16. Young KS. Psychology of computer use: XL. Addictive use of the Internet: A case that breaks the stereotype. Psychol Rep. 1996;79(3 Pt 1):899-902.

17. Leahy, Brian. "Dota Explained and How You Can Play it Now". Shacknews.com. [Internet]. 2010 October 13 [Cited 2018 August 20]Available from: https:/ /www.shacknews. com/article/66007/dota-explained-and-how-you.

18. “Basic Survival - Learn Dota". PlayDota.com. [Internet]. 2012 August 25. [Cited 2018 August 22]. Available from: https:/ / www.playdota.com/threads/welcome-to-reborn.276/.

19. Biessener, Adam. “Valve's New Game Announced, Detailed: Dota 2". Game Informer[Internet]. 2010 October 16[Cited 2018 August 21]. Available from: https://web.archive.org/ web/20101016155010/http:/ /gameinformer.com/b/features/archive/2010/10/13/dota-2-announced-details.aspx.

20. Smith MJ, Thirthalli J, Abdallah AB, Murray RM, Cottler LB. Prevalence of psychotic symptoms in substance users: a comparison across substances. Compr Psychiatry. 2009;50: 245-250.

21. Blaszczhnski A, Walker M, Sharpe L, Nower L. Withdrawal and tolerance phenomenon in problem gambling. Int Gambl Stud. 2008;8:179-192.

22. Dalal PK, Basu D. Twenty years of Internet addiction Quo Vadis? Indian Journal of Psychiatry. 2016 Jan-Mar; 58(1):6-11. 